\title{
Conf $-8708242--1$
}

UCRL 96117

PREPRINT

UCRL--9611?

DE38 008903

\section{DEYELOPHENT OF HIGHLY POLISHED, GRAZING IHCIDENCE IIIRRORS FOR SYNCHROTRON RADIATION BEAM LINES AT SSRL}

\author{
K. GTenn Tirsell \\ E. J. Bergitn \\ B. A. Fuchs \\ F. R. Holdener \\ H. H. Humpal \\ V. P. Karpenko \\ S. Kuikarni \\ Stephen D. Fantone
}

This paper was prepared for submission to the SPIE Conference on XUV Optics and Applications

- Grazing Incidence Optics for Astronomical and Laboratory Applications, August 16-21, 1987,

San Diego, CA

August 1987

This is a preprint of a paper intended for publication in a journal or proceedinga Since changes may be made before publication, this preprint is made available with the understanding that it will not be cited or reproduced without the permisaion of the author.

8861 ¿ 0 AWW 
Development of highly polished, grazing incidence mirrors for synchrotron radiation beam lines at SSRL

K. Glenn Tirsell, E. J. Berglin, 8. A. Fuchs, F. R. Holdener. H. H. Humpal, V. P. Karpenko, and $S$. Kulkarni

Lawrence Livermore National Laboratory

P. D. Box 808, Livermore, Californta 94550

Stephen D. Fantone

Opt:kos Corporation

143 Albany Street, Cambridge, Massachusetts 02139

\begin{abstract}
Hew platinum-coated grazing incidence mirrors with low surface roughnesses have been developed to focus bending magnet radiation from the SSRL/SLAC SPEAR storage ring on the entrance slits of two Beam Line vilt grating monochromators. The first mirror in the toroidal grating monochromator (TGH) branch is a cooled sic cylinder capable of absorbing synchrotron radiation power levels of up to 260 watts without excessive distortion. This mirror deflects the bean vertically through a $12^{\circ}$ angle and focuses it sagitaliy on the ?GM entrance slit plane. The second TGM optical element is a fused-stlica spherical mirror with a large radius of curvature that deflects the beam vertically through an addicional $12^{\circ}$ and rocuses tt tangentialiy with $3 / 1$ demagification. The first mirror in our spherlcal grating branch is a $5^{\circ-v e r t i c a l i y ~ d e f l e c t i n g, ~ c o o l e d ~ s i c ~ t o r o t d ~ d e s i g n e d ~ t o ~ f o c u s ~}$ tangentialiy on the monochromator entrance sitts and 5 agledily on the exit 51 its. A $4^{\circ}$. deflecting fused silicamirror is used after the extt slits in each beam line to refocus on to the sample. For this application a thin cylinder is bent to approximate an ellfpsoid. The mirrors are now installed at SSRL and performance measurements arg plantied. Oualitatively the focus of the TGM optics at the entrance slit plane appears very good. In this paper we discuss considerations leading to the chotce of sic for each of the two first mirrors. We present highlights of the development of these mirrors with some emphasis on Sic polishing techniques. In addition, the specialized metrology developed to produce the more difficult figure of the toroid will be described. Heasured surface roughness and figure results will be presented.
\end{abstract}

\title{
1. INTRODUCTION
}

Several state-of-the art grazing incidence mirrors have been designed, fabricated to our specifications, and installed in Beam Line vill at the Stanford Synchrotron Radiation Laboratory, SSRL. As part of the $x-r a y$ Calloration and Standards Facility Project, Beam Line VIII consists of two general purpose beam lines branching from the same bending magnet source on the SPEAR storage ring. These synchrotron radiation sources, along with a wiggler hard $x-r a y$ line $(B L-X)$ now under construction, have been designed to serve the needs of a participating research team formed by the University of Californfa, and the Lawrence Livermore, Los Alamos, and Sandia Mational Laboratories. Each of the two bending magnet branches has appropriate prefocusing optics, a grating monochromator with three interchangeable gratings, a refocusing mirror, and a sample chamber alloperating in uitrahigh vacuum (UHV). The toroidal grating monochromator (TGM) provides continuousiy tunable radiation in the $8-185 \mathrm{eV}$ range and the spherical grating monochromator (SGM) covers the 60-1100 ev range. The BL-VIII grazing incidence mirrors that are the subject of this paper are al platinum coated and have low surface roughness and figure tolerances required to obtain good $x$-ray reflectivity without excessive scattering losses. The throughput of our beam iines has been enhanced by the high quality of the mirrors that have been developed.

After an overview of beam line optics, we will discuss our grazing incidence mirror development including some detalis of mirror selection. fabrication, surface finish, and mirror mount considerations. Table l summarizes our grazing incidence mirror parameters. The Sic primary mirrors wili be discussed first followed by the fused silica mirrors used down stream. Metrology developed for the sic toroid will be included.

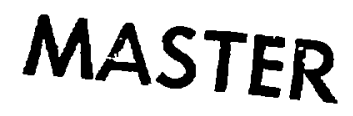


Table 1. Summary of Beam Line VIII Grazing Incidence Mirror Parameters

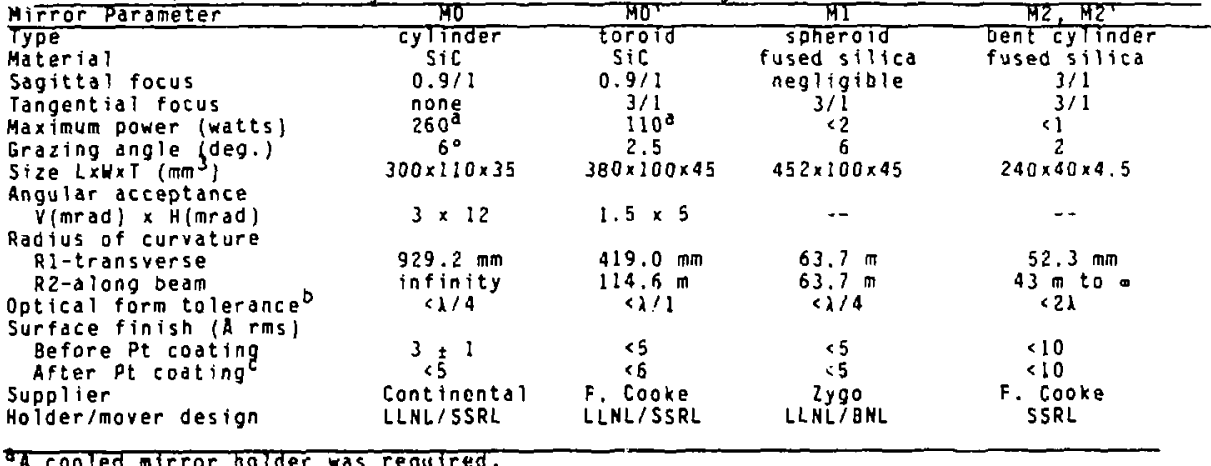

\$h cooTed mirror hotder was required.

At $6328 \mathrm{~A}$.

cplatinum coating $(1000-1500 A)$.

\section{SYHCHROTRON RADIATION BEAM LINE OPTICS}

Figure la shows schematically the $x$-ray optics arrangement for our 6 m TGM beam ithe. The monochemator optics from entrance to exit slits are based on proven designs in use at BHL, HSLS. The îrst mirror in the TGM Oranch, designated as MO, defiects the beam verticaliy through a $12^{\circ}$ angle and focuses it approximately ixl sagitaliy on the TGM entrance slits. Sl. The fused slifca sphertcal mirror Mi then deflects the beam through an additional $12^{\circ}$ and focuses tt tangentialiy with $3 / 1$ demagnification on 51 . The focusing functions of these two mirrors are almost completely independent since the effect of the large Ml radius on the sagittal focus is negligible. In order to design the TGM beall line optics. We made extensive use of the SHADOw ray tracing code developed by $F$. Ceirina and coworkers.? In particular we optimized the position of MI, the Mo location having been constrained by other aicove requirements. It should be noter that the long distance of the first mirrar from the source and alcove wall constraints very significantly influenced our beam line optical design. We confirmed our selection by comparing with many aiternatives such as a flat mirror followed by an ellipsold. Except for the beam's somewhat large horizontat size at SI, the chasen design yields a good match to the grating section. The grating is fully illuminated by a mrad 312 mrad radiation distribution from the SPEAR source as we intended. The horizontal size will be reduced by the proposed SPEAR emittance upgrade.

Three interchangeable toroidal gratings, mounted in a UHV chamber, are the critical dispersive optical elemenss in the monochromator. Wavelength is changed by rotating the operating grating. Bean directions in and out of the grating remain fixed. The toroidal grating refocuses the beam both sagitally and tangentially on the exit slit plane. An exit mirror in turn refocuses the geam on the sample with $3 / 1$ demagnification producing spot sizes of less than $0.5 \times 2 \mathrm{~mm}^{2}$. The beam line features a comparativeiy spacious arrangement of the monochromator and end station on a mezanine. 5 Horeover, we achieved our design goal of bringing the beam into the sample chamber parallel to the mezzanine floor.

Figure ib shows the SGM grating branch optical design. Initially intended for our SPEAR bending magnet, the SGH optics arrangement can be used very well as 2 wiggler sjde branch. 6 optics in this branch are much more grazing due to the lower $x$-ray wavelength range covered (B-220 A). A toroidal first mirror deflects 5 horizontal mrads from the BLVIII bending magnet vertically $5^{\circ}$ upward. The mirror focuses the beam tangentially (nearly verticaliy) into a slightly curyed horizontal line on the SGM entrance slit plane $\$ 1$ and sagitally on the exit sits Sz' nearly $6 \mathrm{~m}$ beyond. 
la

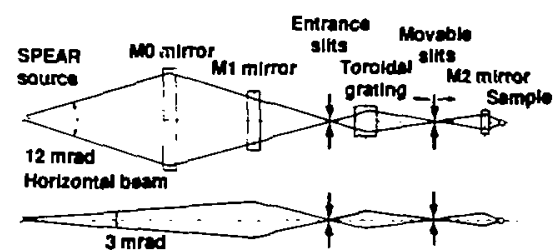

Verikal baem

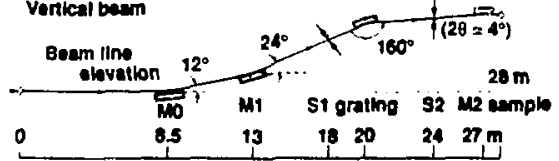

Divtance atong beam IIne, m 1b

Spharical grating monochromator

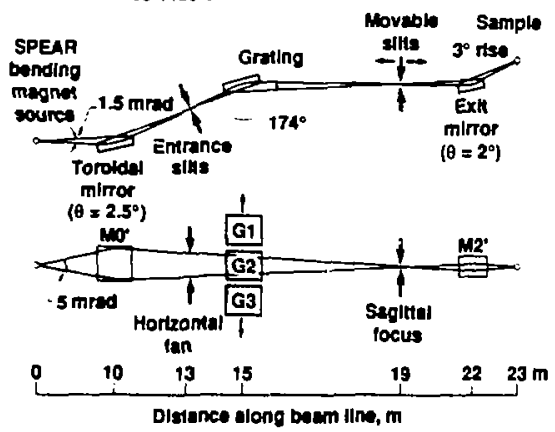

Flgure 1. X-ray optical destgn for Beam Line KIIl at S5RL. a. Toroldal grating branch. b. Spherical grating branch.

Using SHPOOH${ }^{2}$. M. Rowen compared 51 , focal distributions from the torold and fram an alternative prefocusing spherical mirror pair with decoupled sagittal and tangential focusing functions. He assumed nominal SPEAR operation and included mirror refiectivity. He concluded that compered to the dauble mirror system, the toroidal mirror delivers about 70 to $75 \%$ of the flux to the monochromator at 5 -mrad horizontal fan size in splte of the smile shape that the toroid introduces at the 51 . tangential focus. Furthermore the toroid performs better than the pair below roughly 3 mrjd. It will do well in a wiggler side branch ( 2 arad). A more compeling arqument favoring the difficult torold fabrication is that a second prefocusing mirror extends the beam line beyond the avallable space.

System optics from the monochromator entrapce slits to the exit slits are based on a new design due to H. Hogrefz and M. Howells, LBL. The grating is spherical with a 55 m radius that vertically disperses the beam downward deflecting it through a constant total angle of $6^{\circ}$ and focusing it tangentially on the exit slits. Unlike the torold, the large radius of curvature has almost no effect on the sagittal focus. Thus the beam distribution at $\$ 2^{\circ}$ is curvature has almosi than in the case of the TGM. The beam is refocused at the center of a UHY target chamber losated nominally $3 \mathrm{~m}$ from 52 into spot sizes expected to be smaller than $0.5 \times 1 \mathrm{~mm}^{2}$ at the sample. The refocusing mirror in this branch is very similar to that of the TGM branch except that a vertical defiection upward was chosen to bring the SGM beam closer to the horfion at the target.

In the derign of $S R$ beam lines, dominant consideration is the reflectivity of mirrors as a function of grazing angle. Figure 2 shows ideal platinum reflectivity versus photon energy calculated for the $8 L-V i$ I mirrors. The rolloff in reflectivity from two $6^{\circ}$ reflections is well sulted for the TGM photon energy range. The grazing angle chosen for the SGM range is more of a compromise. The rolloff of the single $2.5^{\circ}$ reflection (50 defiection) is not as rapid as we would prefer. On the other hand choosing a larger grazing angle reduces throughpuc throughout the range of interest. The exit mirror rolloff extends weli beyond the end of the monochromator range in both cases.

\section{STC PRIMARY MIRRORS}

Fig 3 shows schematically the first mirror, MO, and mirror mount oriented on SPEAR. optical requirements are severe for such grazing incidence mirrors used to focus SR beams optical requirmenter apericures at several meters. Thermal distortion is of particular concern when large fraction of the incident beam is absorbed as is the case for both of conc primary mirrors. Power levels up to 260 and 110 watts are incident on MO and MO'. respectively. Due to the low SR vertical divergence, the heat deposition tends to produce significant iocalized surface slope distortion. As reported previously, we have used finite element analysts to investigate the effects of thermal/mechanical loading on our two primary mirrors. To keep slope distortion within acceptable limits, we studied different 


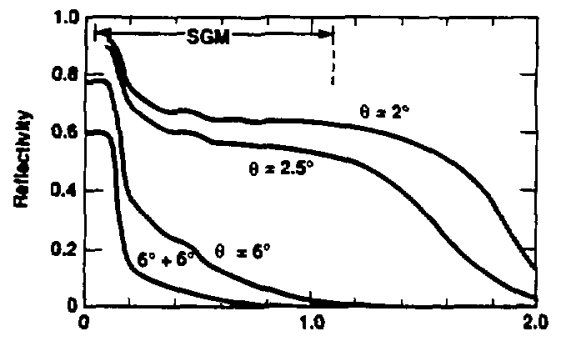

Incldant xeroy enargy, koV

F'gure 2, Calculated platinum mirror x-ray reflectivity for each of our BL-VIII mirrors. The effect of two $6^{\circ}$ reflections (from MO and the Mi) is also shown.

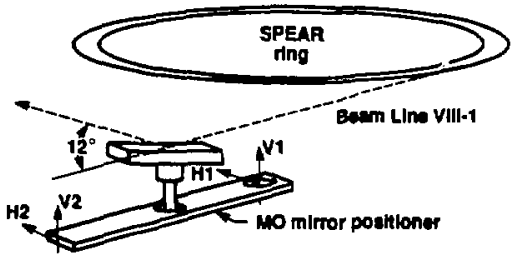

Figure 3. First mirror MO and its positioner shown schematically on SPEAR storage ring.

mirror substrate materials and cooling methods. Rather than aluminum or OFHC copper coated with electroless $\mathrm{Hi}$. we selected commercially avaliable sintered SiC coated with CyO SiC for polishing since tt provides relatively low thermal distortion and avoids certain cost and technical risk factors. (Hote that by using thick CVD-sic. siope distortion can be reduced up to factor of 2.$)$ The greater resistance to thermal stress provided by copper or its alloys is not required for primary inirrors at grazing angles under $10^{\circ}$ on a SPEAR bending magnet.

Dur calculations indicated that conling only by radiation gives unacceptably high surface temperatures. Side cooling is ruled out by the mirror's large width, $110 \mathrm{~mm}$, and by the requirement for passage of radiation very close to Mo on both sides with no cianping al lowed at beam level. Finding that distortion is rather insensitive to the method of conductive cooling, we chose to cool a portion of the bottom surface to limit the surface temperature. Since conductive cooling appears adequate, we did not investigate internal cooling designs. Dur substrate thickness studies showed that Increasing the Mo mirror thickness above $35 \mathrm{~mm}$ (glving a length to thickness ratio of 8.6 ) does not significantly effect the slope distortion. Although the incident power densiey is about 3 times lower for the $2.5^{\circ}$-grazing primary nirror. the expected thermal distortion using fused silica is still not acceptable. since it is roughy 13 times greater than that of sic. Due to this, the progress in our $\dot{s i c}$ polishing technology, Il and the stmilarity of mirror dimensions, we opted for abtaining a sic toroidal mirror and using Mo mirror assembly designs.

The $110 \times 300 \mathrm{~mm}^{2}$ cylindrical mirror Mo was fabricated by the Continental optical Co. from an alpha-sintered blank by Sohto Engineered Materlals. The essential requirement for good polishing was a unfform CVO-SiC $400-\mu m$ layer deposited by the Texas Instruments Co. Final CyD-sic grinding and polifhing processes were aided by a collaborative effort using technology developed at LLNL. II Figure 4 shows the finished cylindrical mirror after plating with platinum.

As described in reference 12 , the $100 \times 380 \mathrm{~mm}^{2}$ toroidal mirror was produced by F. Cooke, Inc. from a similar SiC blank and Cvo SiC layer. The profile metrology developed for the toroid by one of us, 5 . F. is discussed later. Final grinding and poishing was done by Cooke Inc.. in collaboration with one of us, B. F.

Figure 5 shows the toroidal mirror mounted in its water-cooled holder that we designed. The Mo and 5 . mirror holder designs incorporate a new technique for reducing thermal distortion. We applied unequal spring forces distributed along the edges to bend the mirror producing a slight concave profile along its longaxis. This profile is preset to partiy compensate for bending induce by surface heating from the SPEAR source. For this opt imization we used finite element analys is to superiopose slight mechanical preloadinc forces onto tic therma i distortion. Dur final iteration for mo produced a mirror calculated to be ithin 2 arc-sec. for over $70 \%$ of the mirror surface at noninal 3 GeV SPEAR operation. 


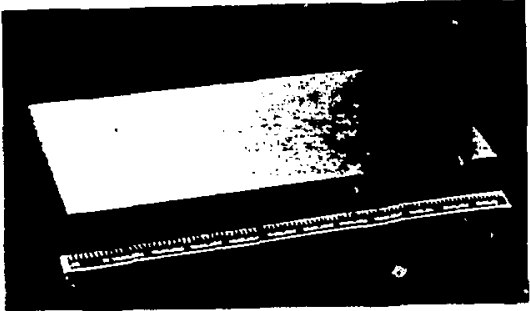

Figure 4. Cylindrical Sic primary mirror MO produced by the Continental optical Co.

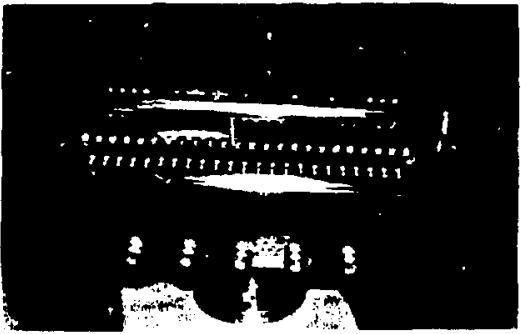

Flgure 5. Toroidal StC mirror MO' produced by $F$. Cooke, inc, mounted in its water-cooled hoider that we designed.

Our primary mirror cooling design provides very good thermal conductivitu from the mirro to a brazed copper-stainless steel cooling block. The UHV requirement led to our use of a commercially avaliable torstondi finger stock. I3 this silver-plated berylifum copper material has excellent thermal properties, and its many torsional fingers each apply a relatively high load over a small area thus providing good thermal contact in vaculim. The spring stiffness and thermal transfer characteristics of the material were confirmed by tests. The materlal is suitable for applications with power densities less than $20: 1 / m^{2}$.

A rigid single post containing cooling tubes is bellows-coupled lnto vacuum to support the mirror, Based on an arrangement developed ond in use at SSRL, the mirror alignment assembly provides stable, mechanically-isolated suppart. 14 Remote vertical and horlzontal adjustments are made relative to a fixed external reference surface located below the chamber as shown schenatically in Figure 3. The roll axis 15 accurately preset. Vertical translation allows complete removal of the mirror from the beam. The mover's long base line contributes to pitch step resolution of about one arcasec allowing precise beam centering.

Figure 6 shows representative SiC mirror surface roughness results taken from a serles of Hyco profiloneter measurements by P. Takacs at BNL. I The MO cyligder results indicate that the mirror is one of the best SiC mirrors of ths type ever made. T5 The schedule prohibited testing the toroidal mirror before platinum coating. Since the results after coating ind cate better than 6 rins. we infer a sub-5 $A$ rms finish for the cvo-sic surface. It is very encouraging that these results can be obtained for a large mirror with such difficult profile.

Figure 7 shows the toroldal mirror mounted in the profile test configuration used during the final polishing operation and schematic drawing of this optical arrangement. The test is based on the fact that the desired toroldal surface ts rery nearly ellipsoidal. The optlcal arrangement was devised so that the toroldal mirror images two polnts ifapproxtmately 10 and $5.3 \mathrm{~m}$ away respectively, onto each otlier with almost no aberration. I6 These two polnts correspond to the foct of the ideal ellipsoid. In the test arrangement. collimated light exits the interferometer and passes through the first negatiye lens which presents to the torold a virtual source approximately $10 \mathrm{~m}$ away. The toroidal mirror reflects the light to form a real image $5.3 \mathrm{~m}$ from its surface. Thus, the light reflected from the mirror is weakly converging towards that remote point. The spherlcal wave front is then colliated by the second negatlve lens. This light is reflected upon itself by the plane mirror and passes back through the lens and torold into the interferometer. The system is double pass, and since we are testing a reflecting surface, the wave front errors are again doubled. The oblique geometry reduces the test sensitirity by the cosine of $86.53^{\circ}$; thus, one fringe in the resulting interferogram, such as that shown in Figure $B$, corresponds to a -wave error in the toroid. The appropriate test geometry is based on the dependence of the angle of incidence, $\theta$, on the saglttal and tangential radii. R $R_{s}$ and $R_{t}$, respectively, given by

$$
\cos ^{2} \theta-R_{s} / R_{t}
$$



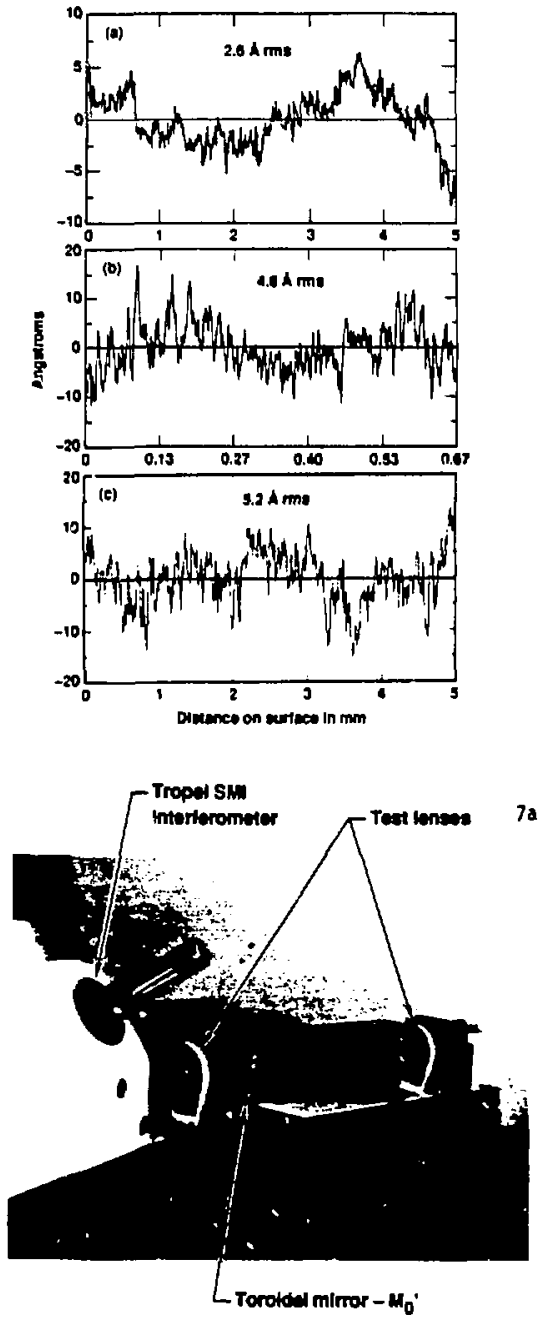

Figure 6. Representative Sic mirror surface roughness measurements made with a Hyko profllometer by Takacs at QNL. a) MO cylinder before Pt coating. b) HO cylinder after Pt coating.

c) Mo' toroid after pt coating.

Figure 7. Toroidal mirror profile optical test arrangement. a) toroid mounted in the test setup. b) profile test geametry. 
This formula predicts an optimum angle of incidence nf $86.569^{\circ}$ that is very close to the value $86.534^{\circ}$ obtained by optimization using the ACCOS $y$ code (a computer program by Scientific Caiculations. Inc.. Fishers. N.Y.). This test setup has a residual comatic error of under 1/4 wave which could be eliminated if a cat's-eye retroreflector were used instead of a plane mirror.

The interferogram in Figure 8 was used to evaluate the mirror profile obtained during the final stages of the mirror fabrication. Note that the fringes are compressed along the long axis due to the test obliquity. The interferogram shows that the mirror is suitably concave and free from irregularities. These optical test results are in agreement with physical measurements by F. Cooke.

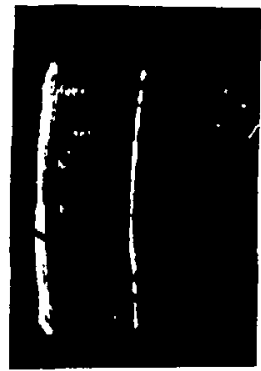

Figure 8. Toroidal mirror profile interferograms showing concavity and abience of irreguiarities. See reference i2.

\section{FUSED SILICA FOCUSING MIRRORS}

\subsection{5pherical prefocusing mirror}

Figure 9 shows the Ml spherical mirror sized to accept the full beam from Mo, as we 11 as the Mi chamber, and mirror alignment mechanism. This design is complicated by the mirror's operating height and angular position, as well as our need for ample clearance below the mirror tank. He constdered a bent-flat fused slica mirror designed to approximate a cylinder. This would have required designing a pew mirror bender for the elevated location. Therefore we opted for a $452 \times 100 \mathrm{~mm}^{2}$ spherical mirror of 64 m $r a d i u s$ fabricated by the Zygo Corp. Fused silica was selected because of the low power levels expected (less than $2 w$ ).

An MI chamber and support frame was designed that was rigidiy attached to the bottom of the $61 \mathrm{~cm}$ thick concrete mezzanine floor. A unique 3 point kinematic mirror support was devised baseä partiy on designs in use at BNL, NSLS. 17 For our application the three support and alignment axes are bellows-coupled into vasuum from the top as shown and attached ta either side of the mirror base. Flexure pivots eliminate backlash from sliding foints. Modeling results indicated that this system is mechanicaliy very stiff and resistant to vibration. Stepper motor drives on each axis give better than 1 arc-sec resolution in pitch, thus meeting our requirement for precise alignment of the beam on the TGM entrance sitts. A commercially avallable controller was grogramed to move the 3 axes in order to produce pure pitch, roll, and elevation motions. I8 The large radius spherical mirror is very insensitive to yaw error. He thus eliminated horizontal translation requirements by making the mirror sufficiently wide to handie anticipated beam excurstons.

Figure 10 is a photograph of the SPEAR beam focus at the TGM entrance slit plane taken during a recent 3 GeV series after alignment of MO and MI mirrors. The aspect ratio and size of the image are reasonable and the beam appears free of scattered components.

\subsection{Refocusting mirror}

Dur -efocusing mirror is based on a proven exit mirror design developed at SSRL. 14 This assembiy features a kinematically mounted UHV chamber housing a thin cylinder of fusedstlica that is bent to simulate an ellipsold. The mirror bender is supported by three vertically criented, micrometer driven axes that provide mirror pitch, roli, and height adjustments. Changing the long radius adjusts the vertical focus of the beam at different target locations along the beam line, an advantage for tandem target chambers. The other refacusing mirror that we considered, an ellipsoid, does not have this flexibility, moreover the ellipsaidal profile entails fabrication difficulties. (See reference 19 , these proceedings). 


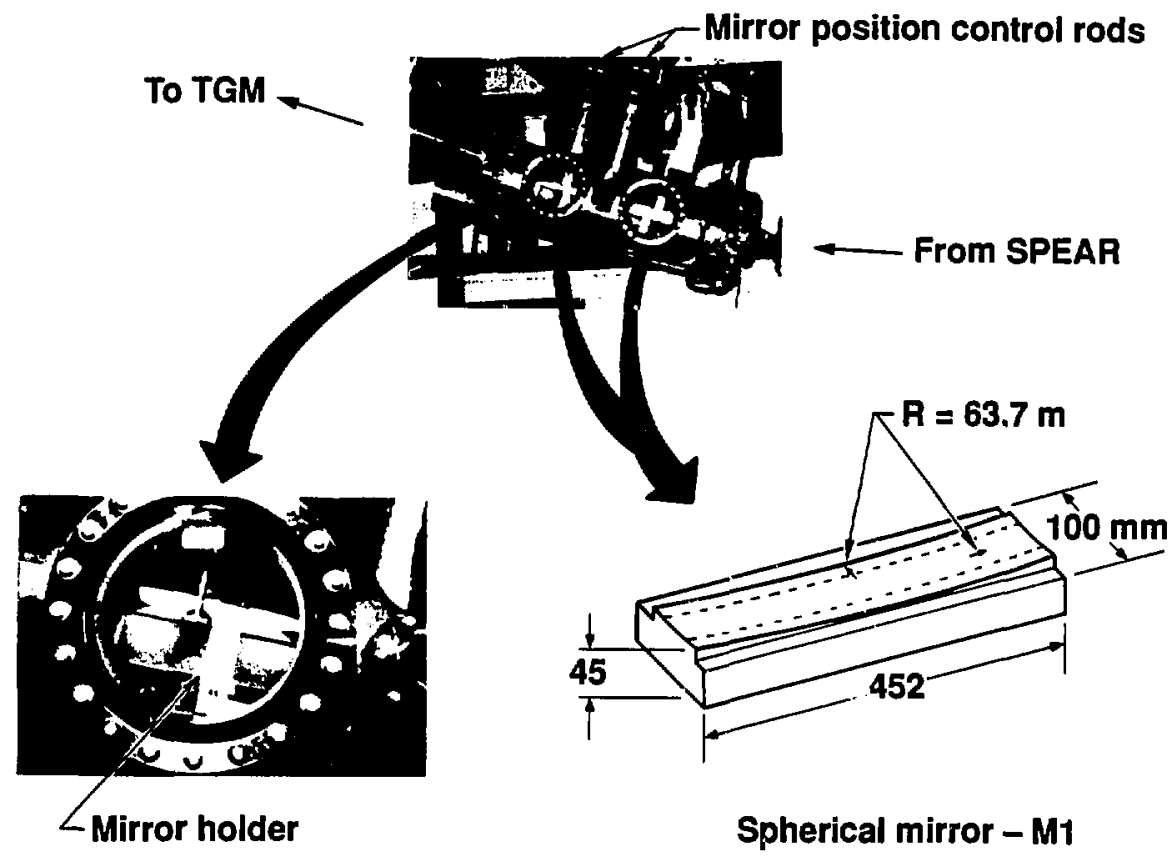

Figure 9. BL-VILI-1 fused silica spherical mirror M1 and its assembly.

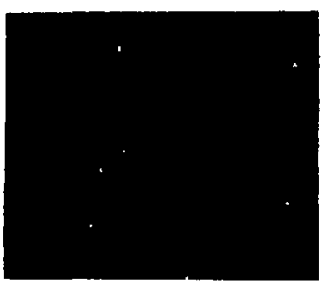

Figure 10, BL-VIII-1 beam focused at the TGM entrance slit plane using the prefocusing mirrors Mo and $M 1$.

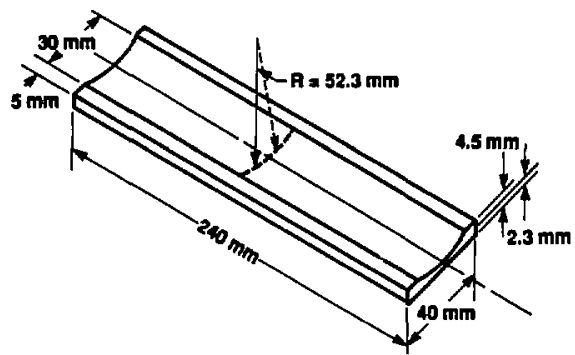

Figure 11. Bent cylindrical fused silica mirror used for refocusing on both BL-VIII branches.

Fabrication of the cylinder is complicated by its thin cross section. Our analysis of bending stresses led to an optimum design of $4.5 \mathrm{~mm}$ thickness and a center thickness of 2.3 mm. as shown in Figure 11. This ylelds a maximum induced tensile bending stress of $2.9 \mathrm{mPa}$ (42l psi) at the bottom surface corresponding to a safety factor of 2.3 . Thinner designs have increasingly higher canter stresses across the $30-m m$ mirror width because the mechanical loading points are on the mirror edges. 
The key to the mirror fabrication by F. Cooke Inc., was careful selection of stress-free fused silica and skilled grinding and polishing procedures during which the thin mirror blank was coupled to a thick fused silica backing biank. The resulting surface finish was better than $10 \mathrm{~A}$ which is acceptable for our refocusing mirror applications.

\section{DISCUSSION ANO CONCLUSIONS}

Several state-of-the art grazing incidence mirrors have been designed, fabricated to our specifications, and installed fn our BL-VIII facility at the Stanford Synchrotron Radiation Laboratory. Major problens for these SR grazing incidence mirrors include beam losses caused by scattering due to surface roughness and figure error. Additional problems for primary mirrors include beam losses due to thermal distortion as wel: as long term degradation of surfaces caused by thermal cycling and radiation damage. our use of back conductively cooled Sic provides a good solution for all of these primary mirror problems for bending magnet power levels up to $300 \mathrm{w}$ and $20 \mathrm{w} / \mathrm{cm}^{2}$ aquivalent normal heat load. For our TGM branch first mirror, a uniform CVD-Sic layer deposited on a cylindrically formed, a loha-sintered SiC substrate has been successfully finished to 3 A rms with the aid of lith poilshing expertise. A less than $5 \lambda$ rms fintsh has also been obtained on a difficult $51 C$ toroid required for SGM branch prefocusing. The successful toroidal mirror fabrication is due in part to the expertise of the manufacturer and to the development of a profile testing method used during production and discussed herein. For the future, we recammend greatly increasing the cro-sic thickness to abtain a factor of 2 decrease ln thermal distortion. Furthermore, efforts should be made to decrease the degradation in surtace rugghness that occurs as a result of the metallic reflective layer depostion.

Our sic mirror holder-cooler concept is now in use on both branch ines. This involves preloading each mirror along tts leng axis to partly compensating for the effect of thermal distortions. The remote alignment system, capable of better than 1 arc-sec. resolution in pitch, has been very satisfaciory.

Designed to provide the TGM tangential focus, the new 63 m-radius, spherical, fused silica mirror has contributed to enhanced TGM throughput. With its triple axis control providing better than 1 arc-sec. pitch resolution, the LLNL designed, top-mounted, mirror holder/positioner assembly has permitted precise beam centering on the TGM entrance sitts. A commercial controller has been programmed to generate pure roll, pitch, and elevation motions. The beam focus and stability at the TGM entrance slits have generally been good throughout our brief experience to date.

Trom aser standpoint, the TGM refocusing mirror has performed better than we expected. The thin, fused silica cylinder ciamped to its SSRL bender/positioner has produced appropriately demagnified, well-defined beam images at the center of the TGM target chamber. The tangential focus is readily controlled and the sagittal focus can be varied by adjusting the mirror's grazing angle. The need for manual micrometer adjustments and lack of decoupled mirror motions is offset by the close proxinity of the mirror to the target chamber allowing good visual feedback. No difficulties with bending stresses have been observed. We are looking forward to obtainting operating experience with the refocusing mirror recently installed in the SGM line and, for that matter, our new SR grazing incidence optics in general.

\section{ACKNOWLEDGMENTS}

It is a pleasure to acknowledge our valuable TGM design collaborations with P. Pianetta and $M$. Rowen, SSRL, and R, S. Hilliams, UCLA. We wish to thank F. Cerrina and co-workers at the University of Hisconsin for developing the SHADOW code and making te avallable to us. He appreciate the very useful discusstons with H. Hogrefe on his optics design, and the guidance of M. R. Howells, LBL, leading to the successfui scim development. A special thanks to R. Fancy. Acton Research Corporation, for his innorative design and dedication in constructing both the toroidal grating and spherical grating monochromator systems. We wish to thank $F$. Cooke for $h$ is excellent work in producing the difficult sic toraidal mirror and the bendable refocusing mirrars and $M$. Ertndel, Continental optical, for skiltful and professional work in producing the Sic cylindricai mirror. We thank S. Laufer and his co-workers at the 2 ygo Corp. for fabricating the large radtis spherical mirror. He appreciate the cooperation of P. Z. Takacs, QNL, in providing surface finish measurements. The surface finish studies of $\mathrm{H}$. J. Brown, LLHL, were fundamental to our success. appreclate the encouragement of $V$. Rehn, Hava 7 Heapons Center, China Lake, CA, and many stimulating discussions concerning SR mirrors. Special thanks go to Richard Boyce, SSRL, who designed and built the refocusing mirror systems and the sic mirror mover assemblies. We wish to thank several members of the LLNL Mechanical Engineering staff for their valuable assistance in the mirror assembly design and construction effort including R. H. Martin for finite element analysis, Ian Murray for innovative design, particularly in the 
use of flexure pivots, H. Goodman and J. Kidd for drafting support, A. Edge for fabrication efforts, J. Lietzke and Brian Kelly for assembly and aliçrment, and D. Erickson for UHV expertice. We also appreciate the technical expertise of $K$. $W$. Neufeld who contributed extensively to the vacuum ind control systems. He appreciate the efforts and advice of John Cerino, SSRL, in guiding the project and in installing, aligning, and commissioning of the TGM branch. Thanks to T. Hostetler, SSRL, for the antire BL VIII installation and A. Waldhauer. SSRL, for installation of both refocusing mirrors. H. Morales and his SSRL staff were invaluable for vacuum component installation and auvice. Our Ml mirror mount design is based on designs by $T$. Oversluizen in use at the National Synchrotron Light Source, BHL. He wish to thank T. Braun for programming the Ml drive indexer and $N$. Schnelder for several enliancenents. He appreciate the continuous support of $C$. Poppe, H. Shotts, and Robert Kuckuck, LLNL, and A. Bienenstock, SSRL, throughout the project. He ars grateful fer the work of Sharin Murray on the manuscript. This work was performed under the auspices of the U. S. Department cf Energy:; the Lawrence Livermore Hational Laboratory under Contract No. H-7405-ENG-4B,

\section{REFERENCES}

1. P. Thiry et al., "A 6 m toroldal-grating moncshromator beam line for high momentumresolution photoelectron spectroscopy, "Nuclear Instrum, and Heth. ¿222 85-90 (1984) and 7. J. Himpsel et al., "First results from a $6 \mathrm{~m} / 10 \mathrm{~m}$ toroidal grat ing monochromator ior soft $x$ rays," Nuclear Instrum. and Meth, 222, 107-110 (1984).

2. 3. Lai and F. Cerrina, "SHADOW: a synchrotron radiation ray tracing program," Nuclear Instrum. and Meth. A246, 337-341 (1986).

3. A. Bienenstock, Stanford Synchrotron Radidion Laboratory, Stanford, CA, private communication, (1985).

4. Gratings were supplied by the Jobin Yron Co., Longjumeau, France: and the monochromator was supplied by the Acton Research, Co.. Acton, MA,

5. The TGM mezzanine layout was done in collaboration with R. S. Wililams, Dept. of Chem. and Biochem., UC.LA, Lo: Angeles, CA.

6. H. Hogrefe, Lawrence gerkeley Laboratory, Berkeley, CA, privete communication, and H. Hogrefe, M. P. Howells, and E. Hoyer. Application of spherical grat ings in synchrotron radiation spectroscopy," Lawrence Berkeley Laboratory, Berkeley, CA, LBL-22070 $(1986)$.

7. M. A. Rowen, Stanford Synchrotron Radiatlon Laboratnry, Stanford, CA, private communication, (April, 1986).

B. Gratings were supplied by Astron Developments, Ltd., Middlesex, U. K. i and the monochromator was supplied by the Acton Research, Co.. Acton, MA.

9. F. R. Holuener ei al.. Thermal loading considerations for synchrotron mirrors," Proc. SPIE 640-Srazing Incidence opt ics, 116-124 (1986).

10. R. Digennaro, M. R. Edwards, and Egon Hoyer. "Predicting thermal distortion of synchrotron radiation mirrors with finite element analys is "Proc. SPIE 582-International Conference on Insertion Devices for Synchrotion Sources, 273-280 (1985).

11. B. A. Fuchs and N. J. Brown, Lawrence Livermore Mational Laboratory, Livermore, CA, - Oevelopment of polishing methods for chenlcal vupor deposited silicon carbide mirrors for synchrotron radiation," UCRL-95892 (1987) and B. A. Fuchs, "Removal rates of chemical vapor deposited silicon carbide (CYo SiC)," these procsedings.

12. F. Cooke, S. Fantone, and B. A. Fuchs, Toroidal mirror of evaporated silicon carbide". Applied 0.ifics 26. 2050-2052 (1987).

13. The silver-plated beryllium copper finger stock. "Multilam" (trade name) is nurmally used a. a high current electrical conductor.

14. These designs were developed by Richard Boyce, Stanford Synchrotron Radiation Laboratory, Stanford, CA, private communication (1985).

15. P. Z. Takacs, Brookhaven National Laboratory, Upton, long Is Iand, NY, private communication $(1986)$. See also P. Z. Takacs, "Metrology of reflected optics for synchrotron radiation," Nuclear Instrum. and Meth. A246, 227-241 (1986).

16. H. $T$. Helford, Aberrations of the Symmetricaloptical System (Academic Press, London, 1974 ), p. 170 .

17. Qur Mi mirror mount design is based partly on designs by T. Oversluizen, National Synchrotron light Source, BNL, Upton, Long Island, NY, private communtcation (19B5).

18. A Compunotor model 3000 indexer was programmed to generate pure Ml motions by $T$. Braun and $K$. H. Neufeld, private communication, Lawrence Livermore National Laboratory, Livermore, CA (1986). Recent modifications were made by M. B. Schneider, Lawrence

Livermore Hational Laboratory, Livermore, CA, (1987).

19. M. Grindel, "Manufacturing and testing of a grazing incidence mirror: "these proceedings. 